\title{
Is venous blood a more reliable description of acid-base state following simulated hypo- and hyperventilation?
}

\author{
Lisha Shastri1 ${ }^{1 *}$, Søren Kjærgaard ${ }^{2}$, Peter S. Thyrrestrup ${ }^{2}$, Stephen E. Rees ${ }^{1}$ and Lars P. Thomsen ${ }^{1}$
}

\begin{abstract}
Background: ABGs are performed in acute conditions as the reference method for assessing the acid-base status of blood. Hyperventilation and breath-holding are common ventilatory changes that occur around the time of sampling, rapidly altering the 'true' status of the blood. This is particularly relevant in emergency medicine patients without permanent arterial catheters, where the pain and anxiety of arterial punctures can cause ventilatory changes. This study aimed to determine whether peripheral venous values could be a more reliable measure of blood gases following acute changes in ventilation.

Methods: To allow for characterisation of ventilatory changes typical of acutely ill patients, but without the confounding influence of perfusion or metabolic disturbances, 30 patients scheduled for elective surgery were studied in a prospective observational study. Following anaesthesia, and before the start of the surgery, ventilator settings were altered to achieve $a+100 \%$ or $-60 \%$ change in alveolar ventilation ('hyper-' or 'hypoventilation'), changes consistent with the anticipation of a painful arterial puncture commonly encountered in the emergency room. Blood samples were drawn simultaneously from indwelling arterial and peripheral venous catheters at baseline, and at 15, 30, 45, 60, 90 and 120 s following the ventilatory change. Comparisons between the timed arterial (or venous) samples were done using repeated-measures ANOVA, with post-hoc analysis using Bonferroni's correction.
\end{abstract}

Results: Arterial blood $\mathrm{pH}$ and $\mathrm{PCO}_{2}$ changed rapidly within the first 15-30s after both hyper- and hypoventilation, plateauing at around 60s ( $\triangle \mathrm{pH}= \pm 0.036$ and $\triangle \mathrm{PCO}_{2}= \pm 0.64 \mathrm{kPa}(4.7 \mathrm{mmHg}$ ), respectively), with peripheral venous values remaining relatively constant until 60 s, and changing minimally thereafter. Mean arterial changes were significantly different at 30s $(P<0.001)$ when compared to baseline, in response to both hyper- and hypoventilation.

Conclusion: This study has shown that substantial differences in arterial and peripheral venous acid-base status can be due to acute changes in ventilation, commonly seen in the ER over the 30 s necessary to sample arterial blood. If changes are transient, peripheral venous blood may provide a more reliable description of acid-base status.

Keywords: Acid-base, Blood gas analysis, Arterial, Venous, Hyperventilation, Hypoventilation

\footnotetext{
* Correspondence: lisha@hst.aau.dk

${ }^{1}$ Respiratory and Critical Care (RCare) group, Aalborg University, Aalborg, Denmark

Full list of author information is available at the end of the article
}

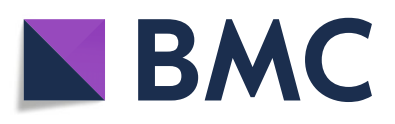

(c) The Author(s). 2021 Open Access This article is licensed under a Creative Commons Attribution 4.0 International License, which permits use, sharing, adaptation, distribution and reproduction in any medium or format, as long as you give appropriate credit to the original author(s) and the source, provide a link to the Creative Commons licence, and indicate if changes were made. The images or other third party material in this article are included in the article's Creative Commons licence, unless indicated otherwise in a credit line to the material. If material is not included in the article's Creative Commons licence and your intended use is not permitted by statutory regulation or exceeds the permitted use, you will need to obtain permission directly from the copyright holder. To view a copy of this licence, visit http://creativecommons.org/licenses/by/4.0/ The Creative Commons Public Domain Dedication waiver (http://creativecommons.org/publicdomain/zero/1.0/) applies to the data made available in this article, unless otherwise stated in a credit line to the data. 


\section{Introduction}

In emergency or intensive care medicine, blood gas analysis is used to monitor the acid-base and oxygenation status of the patient. Small disturbances around the time of sampling could induce acute transient changes in ventilation and misrepresentation of the acid-base status. Such transient changes could be due to anxiety or fear of the needle prior to puncture [1], resulting in hyperventilation or breath holding. Additionally, these changes could also be seen after alterations in ventilator settings or spontaneous breathing in ICU patients [2]. Although common practice is to wait $10 \mathrm{~min}$ or more to measure blood gases after a change in ventilator settings [3], it does not preclude the presence of acute transient changes around the time of sampling, thereby clouding clinical interpretation.

Transient factors affecting blood gases are poorly understood. Studies have demonstrated rapid arterial or venous changes in response to changes in ventilation, but in a non-standard way with volunteers simply requested to hyperventilate to a fixed respiratory frequency or hold their breath [4-6]. Short-term change in ventilation primarily affects blood $\mathrm{pH}$ and $\mathrm{PCO}_{2}$ with little effect on oxygenation unless inspired oxygen levels are low. Due to a larger volume and buffering capacity, the venous blood may not immediately match the changes observed in the arterial blood. This may have several implications related to the interpretation of blood gases at the bedside. Understanding the responses to acute transient changes in both arterial and venous blood are important concepts to consider while interpreting blood gases in emergency and intensive care.

This study investigates the acute response of end-tidal $\mathrm{CO}_{2}\left(\mathrm{EtCO}_{2}\right)$ and, simultaneous arterial and peripheral venous acid-base status, following standardised changes in ventilation, with responses to both an increase and decrease in ventilation being examined.

\section{Methods \\ Patients}

This was a prospective observational study where patients were studied in a surgical milieu allowing for standardisation of ventilator settings. Adult patients without cardiovascular or respiratory disease, scheduled for an elective robot-assisted laparoscopic prostatectomy or hysterectomy were included in the study. This study population allowed for the isolation and characterisation of ventilatory changes to acid-base status without the confounding influence of changes in perfusion, or the presence of metabolic disturbances, known to delay the transit of blood through the tissues. The study was conducted at Aalborg University Hospital North, Aalborg, Denmark, from August 2019 to March 2020, and written informed consent obtained from all the participants prior to the study. The study was approved by the Regional Ethical Committee for North Jutland and abides by the guidelines set in the Declaration of Helsinki.

\section{Protocol}

The study procedure was performed after the patient was anaesthetised but prior to the start of the surgery, during the time when the patient is being prepared for surgery. Patients were anaesthetised according to the department protocol using total intravenous anaesthesia for the duration of the study, with arterial and peripheral venous catheters in-situ. The arterial catheter was inserted into arteria radialis and peripheral venous catheter into a vein in the anterior cubital fossa. Each patient was randomised to receive changes in mechanical ventilation corresponding to either 'hyperventilation' or 'hypoventilation' as described below.

\section{Study procedure and blood sampling}

Blood sample pairs were taken by two trained individuals, simultaneously drawing an arterial and a venous sample. The individuals were aware of the changes in ventilation as well as the catheter from which they were sampling, however, we do not expect this to result in systematic bias in relation to the sampling. Sample pairs were taken at baseline ( 2 pairs immediately after each other) and then at 15, 30, 45, 60, 90 and $120 \mathrm{~s}$ after the change in ventilation. Blood was collected in preheparinised safePICO syringes (Radiometer, Copenhagen, Denmark) with $1 \mathrm{~mL}$ of blood per sample. The syringes were capped, and air bubbles removed immediately after sampling. The baseline samples were analysed prior to the start of the experiment, to allow all samples to be analysed within $30 \mathrm{~min}$ of sampling without storage on ice, as recommended by IFCC guidelines [7]. A third person ensured correct timing of the sampling and assisted in capping the syringes at the time of sampling. Samples were analysed in the order that they were taken, arterial before venous, on the same ABL800 Flex analyser (Radiometer, Copenhagen, Denmark).

\section{Ventilator settings}

Ventilator settings at baseline and for 'hyperventilation' and 'hypoventilation' are illustrated in Table 1. Patients

Table 1 Ventilatory settings during baseline and for hyperventilation and hypoventilation

\begin{tabular}{llll}
\hline Parameters & Baseline & Hyperventilation & Hypoventilation \\
\hline Tidal volume $\left(\mathrm{V}_{\mathrm{T}}\right)$ & $6 \mathrm{ml} / \mathrm{kg}$ & $8 \mathrm{ml} / \mathrm{kg}$ & $6 \mathrm{ml} / \mathrm{kg}$ \\
Respiratory Rate $(\mathrm{RR})$ & $15 \mathrm{bpm}$ & $20 \mathrm{bpm}$ & $6 \mathrm{bpm}$ \\
PEEP & $5 \mathrm{cmH}_{2} \mathrm{O}$ & $5 \mathrm{cmH}_{2} \mathrm{O}$ & $5 \mathrm{cmH}_{2} \mathrm{O}$ \\
Criteria for termination & & $\mathrm{EtCO}_{2}<1.5 \mathrm{kPa}$ & $\mathrm{sPO}_{2}<88 \%$ \\
& & & $\mathrm{EtCO}_{2}>6.5 \mathrm{kPa}$ \\
\hline
\end{tabular}


were ventilated using IPPV ventilation with a volumecontrolled mode (Dräger Primus', Lübeck, Germany). Changes in ventilation approximated to either a $100 \%$ increase or $60 \%$ decrease in alveolar ventilation $\left(\dot{\mathrm{V}}_{\mathrm{A}}\right)$. $\dot{\mathrm{V}}_{\mathrm{A}}$ was calculated from tidal volume $\left(\mathrm{V}_{\mathrm{T}}\right)$, anatomical dead space $\left(V_{D}\right)$ and respiratory rate $(R R)$ from $\dot{V}_{A}=\left(V_{T}\right.$ $\left.V_{D}\right) \cdot R R$, assuming a $V_{D}$ of $150 \mathrm{ml}$. For example, in a patient with an ideal body weight of $75 \mathrm{~kg}$ and baseline $\mathrm{V}_{\mathrm{T}}=6 \mathrm{ml} / \mathrm{kg}$ and $\mathrm{RR}=15$ breaths per $\min (\mathrm{bpm}), \dot{\mathrm{V}}_{\mathrm{A}}$ would equal $((6 \cdot 75)-150) \cdot 15=4500 \mathrm{ml} / \mathrm{min}$. A $100 \%$ increase, and $60 \%$ decrease, in $\dot{\mathrm{V}}_{\mathrm{A}}$ would result in values of 9000 and $1800 \mathrm{ml} / \mathrm{min}$, respectively. Typically, in the emergency department (ED), hyperventilation can result in respiratory rates as high as $30 \mathrm{bpm}$ and hypoventilation can present as complete apnea if the patient holds their breath. As complete cessation of ventilation was not desirable for this protocol, a reduction of $60 \%$ was considered safe by the study team. An increase of normal respiratory rate from 15 to $30 \mathrm{bpm}$ represents a $100 \%$ increase in alveolar ventilation, we therefore selected an increase in 100\%, however increasing both tidal volume and respiratory rate, so as to simulate a more normal pattern of breathing for the patient. $\mathrm{EtCO}_{2}$ and $\mathrm{SpO}_{2}$ were monitored throughout the study; $\mathrm{EtCO}_{2}$ continuously measured using Beacon Caresystem (Mermaid Care A/S, Nørresundby, Denmark) and $\mathrm{SpO}_{2}$ using pulse oximetry. The acute transient change in ventilation lasted $2 \mathrm{~min}$ so as to characterise typical short-term changes in ventilation.

\section{Sample size calculation}

The studies by Montagna et al. [5] and Steurer et al. [4] examined the effect of hyperventilation on blood gases. From their results we approximated the changes from baseline for $\mathrm{PCO}_{2}$ in both arterial and venous blood respectively, following voluntary hyperventilation. We used the mean and SD at baseline of $0 \pm 0.5 \mathrm{kPa}$ reported in [5], and the arteriovenous difference in $\mathrm{PCO}_{2}$ of 0.85 $\mathrm{kPa}$, reported in $[4,5], 1 \mathrm{~min}$ into the hyperventilation period. For the SD at $1 \mathrm{~min}$, we expected a slightly higher variance than that at baseline, and therefore chose an SD of $0.8 \mathrm{kPa}$. The calculated sample size using the data from baseline and at $1 \mathrm{~min}$ was therefore $12 \mathrm{pa}$ tients each, for the hyper- and hypoventilation parts of the study, with $\alpha=0.05$ and $\beta=0.80$. Ethical approval was obtained to study 30 patients.

\section{Statistical analysis}

Variability of the arterial and venous blood were examined using the two pairs at baseline, which were taken immediately after each other. This was analysed using a Bland-Altman (BA) comparison, calculating biases and limits of agreement (LoA) for arterial and venous $\mathrm{pH}$ and $\mathrm{PCO}_{2}$ at baseline under steady state conditions for ventilation.

Changes following hyper- or hypoventilation were analysed as changes $(\Delta)$ in $\mathrm{pH}, \mathrm{PCO}_{2}$ and $\mathrm{EtCO}_{2}$ from baseline. Tests of normality were performed using Shapiro-Wilk's test, and the data were found to be normally distributed. Comparisons between the timed arterial samples were analysed using a repeated measures ANOVA followed by a post-hoc analysis using Bonferroni's correction to compare differences between the average values at each timepoint from baseline. Similar analyses were done for the peripheral venous samples and the $\mathrm{EtCO}_{2}$ measurements. All results are presented as mean $\pm \mathrm{SD}$, with $P<0.05$ considered statistically significant. Statistical analysis was conducted on SPSS v25 (SPSS ${ }^{\odot}$ IBM Corp., Armonk, USA).

\section{Results}

Thirty patients were studied, with 15 patients each in the hyper- and hypoventilation parts of the study. The mean age of the patients were 61 years and $27 \%$ were female. Further details are presented in Table 2.

\section{Variability of $\mathrm{pH}$ and $\mathrm{PCO}_{2}$ at baseline steady-state ventilation}

The bias and LoA of $\mathrm{pH}$ and $\mathrm{PCO}_{2}$ values at baseline ventilation were, for arterial blood $0.001(-0.004$ to $0.006)$ and $-0.11(-0.25$ to 0.03$) \mathrm{kPa}$ (or $-0.83(-1.88$ to 0.22$) \mathrm{mmHg}$ ), and for peripheral venous blood 0.001 ( -0.005 to 0.007$)$ and $-0.01(-0.20$ to 0.17$) \mathrm{kPa}$ (or 0.08

Table 2 Population characteristics ( $n=30)$, baseline blood gas values are a mean of two samples taken immediately after each other

\begin{tabular}{lc}
\hline Parameters & Mean \pm SD or $\mathbf{N}$ (\%) \\
\hline Age (years) & $61 \pm 10$ \\
Sex- Female & $8(26.7)$ \\
Height (cm) & $176 \pm 7$ \\
Weight (kg) & $84.8 \pm 12.6$ \\
Surgery & \\
$\quad$ Prostatectomy & $22(73.3)$ \\
Hysterectomy & $8(26.7)$ \\
Arterial (baseline) & \\
$\mathrm{pH}$ & $7.409 \pm 0.035$ \\
$\mathrm{PCO}_{2}$ (kPa) & $5.55 \pm 0.64$ \\
$\mathrm{PCO}_{2}$ (mmHg) & $41.63 \pm 4.80$ \\
Venous (baseline) & \\
$\mathrm{pH}$ & $7.391 \pm 0.034$ \\
$\mathrm{PCO}_{2}$ (kPa) & $6.02 \pm 0.73$ \\
$\mathrm{PCO}_{2}$ (mmHg) & $45.15 \pm 5.48$ \\
$\mathrm{EtCO}_{2}$ (baseline; $\mathrm{kPa}$ ) & $4.67 \pm 0.62$ \\
$\mathrm{EtCO}_{2}$ (baseline; $\left.\mathrm{mmHg}\right)$ & $35.03 \pm 4.65$ \\
\hline
\end{tabular}


(- 1.50 to 1.28$) \mathrm{mmHg}$ ), respectively (BA plots not shown). The widest LoAs of the variability of the arterial and venous $\mathrm{pH}$ and $\mathrm{PCO}_{2}$ are incorporated in Fig. 1 as horizontal dotted lines to represent the blood's inherent variability.

\section{Responses to hyper- and hypoventilation}

The changes from baseline $(\Delta)$ in $\mathrm{EtCO}_{2}$, arterial and peripheral venous blood, are shown in Fig. 1 as averages and SD (one-sided) for all patients. Changes in $\mathrm{pH}$, $\mathrm{PCO}_{2}$ and $\mathrm{EtCO}_{2}$ in response to hyperventilation are displayed in Fig. $1 \mathrm{a} \& \mathrm{~b}$ and in response to hypoventilation in Fig. 1c \& d, respectively. No patient reached termination criteria during the course of the study.
Following an acute transient increase in ventilation, arterial $\mathrm{pH}$ and $\mathrm{PCO}_{2}$ changed faster than in peripheral venous blood, with a rapid and statistically significant change from baseline initiated within the first 30s $(P<$ $0.001)$, plateauing around $60 \mathrm{~s}(\Delta \mathrm{pH}=0.036 \pm 0.010$ and $\left.\Delta \mathrm{PCO}_{2}=-0.64 \pm 0.14 \mathrm{kPa}(-4.77 \pm 1.07 \mathrm{mmHg})\right)$. Venous blood parameters changed after $90 \mathrm{~s}$, remaining minimal and not significantly different from baseline. An acute transient decrease in ventilation changed arterial $\mathrm{pH}$ and $\mathrm{PCO}_{2}$ faster than hyperventilation, with changes in arterial acid-base status observed as early as 15s. Arterial values of $\mathrm{pH}$ and $\mathrm{PCO}_{2}$ were significantly different from baseline at $30 \mathrm{~s}(P<0.001)$, with responses reaching $-0.038 \pm 0.007$ and $0.75 \pm 0.11 \mathrm{kPa}(5.59 \pm 0.85 \mathrm{mmHg})$ for $\Delta \mathrm{pH}$ and $\Delta \mathrm{PCO}_{2}$, respectively, at $60 \mathrm{~s}$. Venous $\mathrm{pH}$ was significantly different from baseline at $60 \mathrm{~s}(P<0.01)$
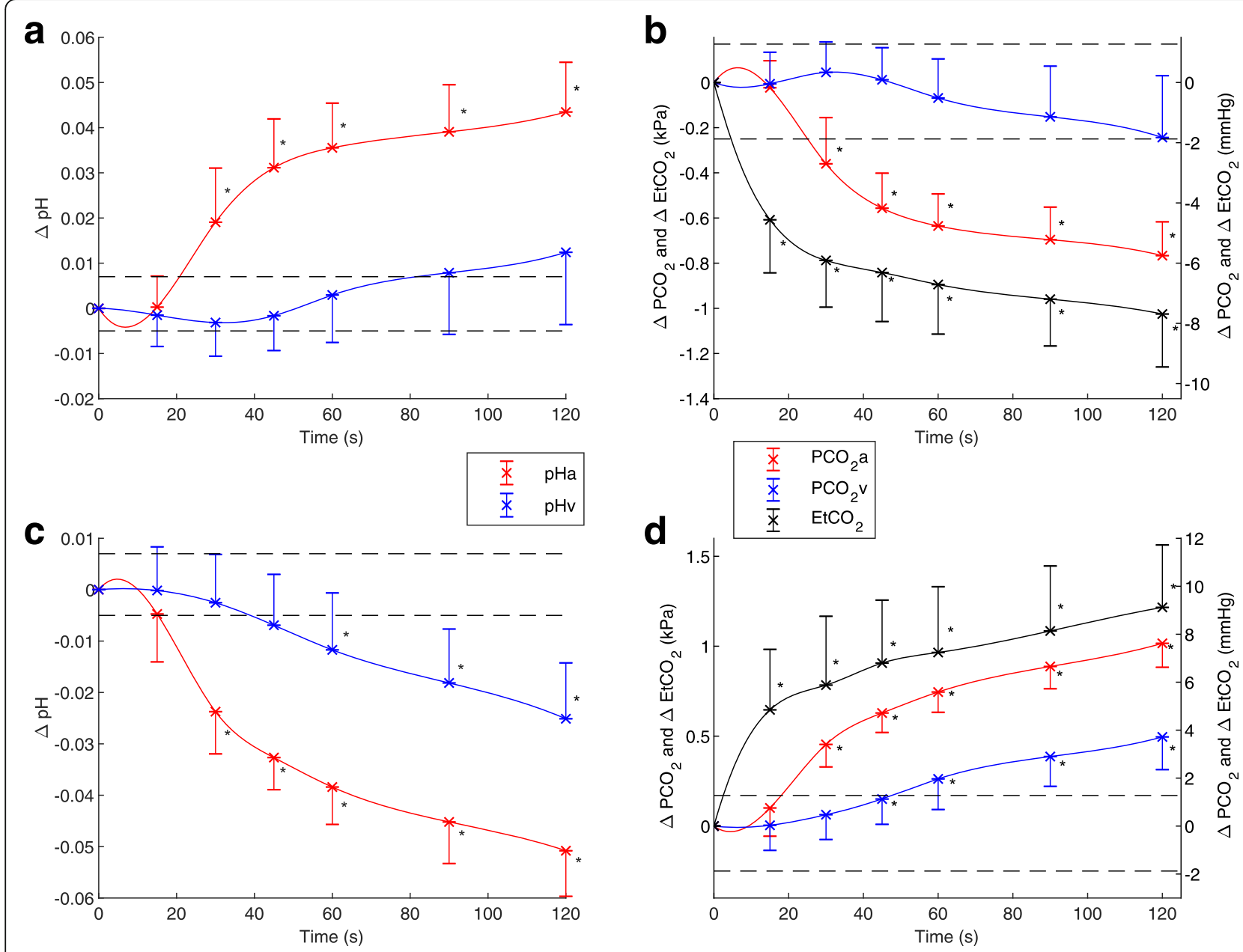

Fig. 1 Changes in end-tidal $\mathrm{CO}_{2}$, arterial and peripheral venous $\mathrm{pH}$ and $\mathrm{PCO}_{2}(\mathrm{kPa}, \mathrm{mmHg})$ in response to hyper- $(\mathbf{a}$, b) and hypoventilation $(\mathbf{c}$, d). Changes in end-tidal $\mathrm{CO}_{2}$ (EtCO $;$; black), arterial (red) and peripheral venous (blue) pH and $\mathrm{PCO}_{2}$ plotted as a change from baseline $(\Delta)$ in response to hyperventilation $(\mathbf{a} \& \mathbf{b})$ and hypoventilation $(\mathbf{c} \& \mathbf{d})$. Data presented as mean \pm SD. Error bars (only one side shown) represent SD at that time point. Dotted black horizontal lines represent the widest LoAs of the variability at baseline in the arterial and peripheral venous blood

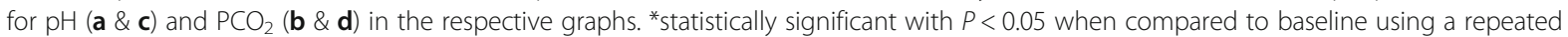
measures ANOVA followed by a post-hoc test with Bonferroni's correction 
and $\mathrm{PCO}_{2}$ at $45 \mathrm{~s}(P<0.002)$. Arterial $\mathrm{PCO}_{2}$ followed the trend of $\mathrm{EtCO}_{2}$ with a minimal delay of $15 \mathrm{~s}$ between them in response to both hyper- and hypoventilation. $\mathrm{EtCO}_{2}$ was significantly different from baseline $15 \mathrm{~s}$ after the change in ventilation $(P<0.001)$.

\section{Discussion}

Acid-base and oxygenation status are important measurements, needed for the management of patients in intensive and emergency care. Acute transient changes in ventilation can rapidly affect these parameters in arterial blood. This study has shown that standardised increases and decreases in ventilation result in a reproducible pattern of rapid changes in arterial $\mathrm{pH}$ and $\mathrm{PCO}_{2}$ seen as quickly as 30s in accordance with the speed of changes in the lungs $\left(\mathrm{EtCO}_{2}\right)$. Peripheral venous blood is less responsive to these changes, presenting first after $60 \mathrm{~s}$, meaning venous blood essentially filters out changes due to short term variability in ventilation. Previous studies have shown that voluntary hyperventilation can induce a rapid change in the arterial (5) or venous (13) blood, with a maximal change observed at $\sim 2$ min for arterial and $\sim 4$ min for venous blood. The lack of standardisation in these studies make it difficult to determine and compare the precise response of blood gases to the changes in ventilation, with this study being the first to investigate responses to standard changes in ventilation.

Repeated blood sampling is associated with anxiety and fear in the patient, especially in those with chronic illnesses [8]. This anxiety could manifest due to numerous reasons, for example in anticipation of the next puncture or in response to the pain of the needle prick [8-10], thereby precipitating momentary changes in respiratory patterns including hyperventilation and breathholding $[11,12]$, commonly encountered in the emergency room, in admitted patients with COPD, or for awake patients on non-invasive ventilation. Transient changes can also be observed in intensive care, when patients on assisted ventilation engage in spontaneous breathing [2]. Janssens et al. [13] studied the response of hypercapnic patients to initiation or interruption of noninvasive positive pressure ventilation and demonstrated a change in $\mathrm{PaCO}_{2}$ of $2-2.7 \mathrm{kPa}(15-20 \mathrm{mmHg})$, within the first $2 \mathrm{~min}$, which are much larger than the changes evidenced in this study.

In a survey conducted by Rang et al. [14], discussing the clinical significance of variation in blood gases, emergency physicians suggest that a difference in $\mathrm{PCO}_{2}$ of $0.8 \mathrm{kPa}(6 \mathrm{mmHg})$ is clinically significant. In our study, we see an average change in $\mathrm{PaCO}_{2}$ of 0.64 and $0.75 \mathrm{kPa}$ at the end of $1 \mathrm{~min}$ in response to hyperventilation and hypoventilation, which in combination with the SDs describing variation at baseline gives a range of $\sim 1$ $\mathrm{kPa}(7.5 \mathrm{mmHg})$, at or above the clinically significant range described by Rang et al. The transient changes in arterial acid-base seen here many be similar to, or even lower than, those seen in departments of emergency or pulmonary medicine, with the ventilatory changes applied in this study relatively small when compared to hyperventilation (up to $30 \mathrm{bpm}$ ) or breath-holding, frequently encountered in the ED. In addition, the duration of this protocol is consistent with brief periods of hyperventilation or breath holding and corresponds to the duration of a typical arterial puncture which takes around 30s to perform by a trained individual [9], with additional time required for patient preparation [15].

In contrast, peripheral venous blood showed a smaller and a more delayed response of over 30s longer than that in the arterial blood. A reason for this could be slowing down of blood flow in the peripheral capillaries in combination with the sluggish flow in the veins. The large volume of interstitial fluid that equilibrates with the arterial blood before it reaches the veins, could induce an additional, but minor delay between these two compartments [16-18]. While the significant differences between the arterial and venous systems described in this study are a result of isolated effects of ventilation, in the ED and other departments treating acutely ill patients, it is likely for there to be other problems, including poor perfusion and other metabolic issues. This will presumably further slow the transit of blood in the tissues, thereby further delaying the venous response.

Given the acute transient differences in acid-base status shown here, the question arises as to whether the venous or arterial gases are a more accurate, or perhaps stable, description of patient state. This study shows that if ventilation changes are acute and transitory, then the venous values might be a more reliable representation of the patient's acid-base status, filtering out these transient changes, and providing further evidence for the increasing trend of using venous blood as a screening tool in the ED. If, however, changes are acute but nontransitory, i.e. maintained over a period of more than the couple of minutes investigated here, then it is clear that care should be taken to measure arterial samples in steady state, and to allow further time for the equilibration of venous blood, which is likely to be delayed in relation to arterial blood.

The major limitation of the study was that blood sampling was ended at $2 \mathrm{~min}$ to investigate the fast response due to acute transient changes in ventilation, and does not investigate the delay in venous blood in relation to arterial over a longer duration. Characterisation of these short-term dynamics, however, is novel, and no previous data exists with paired arterial-venous sampling performed every $15 \mathrm{~s}$. 


\section{Conclusion}

In conclusion, this study has shown that substantial differences in arterial and peripheral venous acid-base status can be due to acute changes in ventilation. If these changes are transient, peripheral venous blood may provide a more reliable description of acid-base status. Most importantly, if an ABG is used for quantification of acidbase status, these results indicate that it must only be in situations of stable ventilation.

\section{Abbreviations}

ABG: Arterial blood gas; ANOVA: Analysis of variation; BA plot: Bland-Altman plot; COPD: Chronic obstructive pulmonary disease; $\mathrm{EtCO}_{2}$ : End tidal carbon dioxide; ICU: Intensive Care Unit; LoA: Limits of agreement; $\mathrm{PCO}_{2}$ : Partial pressure of carbon dioxide; SD: Standard deviation; $\mathrm{SpO}_{2}$ : Peripheral saturation of oxygen

\section{Acknowledgements}

Not Applicable.

\section{Authors' contributions}

LS, LPT, SK and SER conceptualised the study. LS, LPT, PST and SK conducted the study. LS, LPT and SER analysed the data, and all authors contributed to the interpretation of the results and writing of the manuscript. All authors read and approved the final manuscript.

\section{Funding}

The research group of LS, SER and LPT receive research money from OBI Medical A/S

\section{Availability of data and materials}

The datasets used and/or analysed during the current study are available from the corresponding author upon reasonable request.

\section{Ethics approval and consent to participate}

The study was approved by the Regional Ethical Committee for North Jutland (N-20190014).

\section{Consent for publication}

Not applicable.

\section{Competing interests}

SER and SK were previous shareholders of OBI Medical A/S.

\section{Author details}

${ }^{1}$ Respiratory and Critical Care (RCare) group, Aalborg University, Aalborg, Denmark. ${ }^{2}$ Department of Anaesthesiology and Intensive Care, Aalborg University Hospital North, Aalborg, Denmark.

Received: 27 October 2020 Accepted: 5 February 2021

Published online: 17 February 2021

\section{References}

1. Kose S, Mandiracioglu A. Fear of blood/injection in healthy and unhealthy adults admitted to a teaching hospital. Int J Clin Pract. 2007:61:453-7.

2. Putensen $C$, Muders $T$, Varelmann D, Wrigge $H$. The impact of spontaneous breathing during mechanical ventilation. Curr Opin Crit Care. 2006;12:13-8.

3. Cakar N, Tu M, Demirarslan A, Nahum A, Adams A, Akyncy O, et al. Time required for partial pressure of arterial oxygen equilibration during mechanical ventilation after a step change in fractional inspired oxygen concentration. Intensive Care Med. 2001;27:655-9.

4. Steurer J, Hoffmann U, Dür P, Russi E, Vetter W. Changes in arterial and transcutaneous oxygen and carbon dioxide tensions during and after voluntary hyperventilation. Respiration. 1997;64:200-5.

5. Montagna P, Paniccia M, Marchello L, Riva R. Hyperventilation in normal subjects. A clinical, gas-analytic and EMG study. Electroencephalogr Clin Neurophysiol. 1995;97:159-63.
6. Sasse SA, Berry RB, Nguyen TK, Light RW, Kees MC. Arterial blood gas changes during breath-holding from functional residual capacity. Chest. 1996;110:958-64.

7. Burnett RW, Covington AK, Fogh-Andersen N, Külpmann WR, Maas AHJ, Müller-Plathe O, Siggaard-Andersen O, Van Kessel AL, Wimberley PD, Zijlstra WG. Approved IFCC recommendations on whole blood sampling, transport and storage for simultaneous determination of $\mathrm{pH}$, blood gases and electrolytes. Eur J Clin Chem Clin Biochem. 1995;33:247-53.

8. McLenon J, Rogers MAM. The fear of needles: a systematic review and meta-analysis. J Adv Nurs. 2019;75:30-42.

9. Patout $\mathrm{M}$, Lamia $\mathrm{B}$, Lhuillier $\mathrm{E}$, Molano $\mathrm{L}$. A randomized controlled trial on the effect of needle gauge on the pain and anxiety experienced during radial arterial puncture. PLoS One. 2015;10:e0139432.

10. Shave K, Ali S, Scott SD, Hartling L. Procedural pain in children: a qualitative study of caregiver experiences and information needs. BMC Pediatr. 2018;18: 324.

11. Boiten FA. The effects of emotional behaviour on components of the respiratory cycle. Biol Psychol. 1998;49:29-51.

12. Masaoka Y, Homma I. Anxiety and respiratory patterns: their relationship during mental stress and physical load. Int J Psychophysiol. 1997;27:153-9.

13. Janssens JP, Howarh-Frey C, Chevrolet JC, Abajo B, Rochat T. Transcutaneous $\mathrm{PCO}_{2}$ to monitor noninvasive mechanical ventilation in adults: assessment of a new transcutaneous $\mathrm{PCO}_{2}$ device. Chest. 1998;113: 768-73.

14. Rang LCF, Murray HE, Wells GA, MacGougan CK. Can peripheral venous blood gases replace arterial blood gases in emergency department patients? Can J Emerg Med. 2002;4:7-15.

15. Giner J, Casan P, Belda J, González M, Ma Miralda R, Sanchis J. Pain during arterial puncture. Chest. 1996;110:1443-5.

16. Schlichtig R, Grogono AW, Severinghaus JW. Current status of acid-base quantitation in physiology and medicine. Anesthesiol Clin North America. 1998;16:211-33.

17. Rees SE, Andreassen S. Mathematical models of oxygen and carbon dixide storage and transport: the acid-base chemistry of blood. Crit Rev Biomed Eng. 2005;33:209-64

18. Andreassen S, Rees SE. Mathematical Models of Oxygen and Carbon Dioxide Storage and Transport: Interstitial Fluid and Tissue Stores and Whole-Body Transport. Crit Rev Biomed Eng. 2005;33(3):265-98.

\section{Publisher's Note}

Springer Nature remains neutral with regard to jurisdictional claims in published maps and institutional affiliations.
Ready to submit your research? Choose BMC and benefit from:
- fast, convenient online submission
- thorough peer review by experienced researchers in your field
- rapid publication on acceptance
- support for research data, including large and complex data types
- gold Open Access which fosters wider collaboration and increased citations
- maximum visibility for your research: over $100 \mathrm{M}$ website views per year
At BMC, research is always in progress.
Learn more biomedcentral.com/submissions 